CLINICAL STUDY

\title{
A meta-analysis of the effect of lowering serum levels of GH and IGF-I on mortality in acromegaly
}

\author{
I M Holdaway, M J Bolland ${ }^{1}$ and G D Gamble ${ }^{1}$ \\ Department of Endocrinology, Greenlane Clinical Centre and Auckland City Hospital, PO Box 92 189, Auckland 1142, New Zealand and ${ }^{1}$ Department of \\ Medicine, Auckland School of Medicine, University of Auckland, Auckland, New Zealand
}

(Correspondence should be addressed to I M Holdaway; Email: ian@adhb.govt.nz)

\begin{abstract}
Objective: Formal studies of acromegaly have found increased mortality associated with the disorder, although reduction of serum levels of GH and IGF-I by treatment appears to improve survival. A metaanalysis of mortality studies in acromegaly has thus been performed to assess the effect of lowering serum GH and IGF-I on survival.

Design and methods: Medline was searched for studies under 'acromegaly', 'mortality' and 'cause of death' (1965-2008), and abstracts of recent meetings of the US Endocrine Society were hand searched. Studies were restricted to those presenting mortality data according to serum GH and IGF-I at last follow-up, and with mortality expressed as a standardized mortality ratio (SMR).

Results: Patients with random serum GH $<2.5 \mu \mathrm{g} / \mathrm{l}$ following treatment, mostly measured by standard RIA, had mortality close to expected levels (SMR 1.1, 95\% confidence interval (CI) 0.9-1.4) compared with an SMR of 1.9 (95\% CI 1.5-2.4) for those with final GH >2.5 $\mu \mathrm{g} / \mathrm{l}$. Similarly, a normal serum IGF-I for age and sex at last follow-up after treatment was associated with an SMR of 1.1 (95\% CI 0.91.4) compared with an SMR of 2.5 (95\% CI 1.6-4.0) for those with continued IGF-I elevation. There was a significant trend for reduced mortality in series reporting frequent use of somatostatin analogues and in studies reporting high $(>70 \%)$ rates of biochemical remission after treatment.

Conclusions: Clinicians treating acromegalic patients should aim for random serum GH $<2.5 \mu \mathrm{g} / \mathrm{l}$ measured by RIA (probably $<1 \mu \mathrm{g} / \mathrm{l}$ measured by modern sensitive immunoassay) and normal serum IGF-I values, to restore the elevated mortality of the condition to normal levels.
\end{abstract}

European Journal of Endocrinology 159 89-95

\section{Introduction}

Acromegaly is a state of chronic growth hormone $(\mathrm{GH})$ excess associated with a range of complications including soft tissue overgrowth, hypertension, diabetes, obstructive sleep apnoea, arthropathy and impaired cardiac function. Estimates of mortality from older studies indicate that despite traditional forms of treatment, including pituitary surgery and radiotherapy, death rates in the disorder were significantly elevated compared with the general population (1). This increased mortality has been attributed mainly to increased rates of death from cardiovascular disease, stroke and a possible increase in death rates from cancer. However, more recent reports have found a lesser impact of acromegaly on mortality, with the 95\% confidence intervals (CI) from standardized mortality ratios (SMRs) often overlapping unity. It seems likely that these improved mortality estimates reflect better techniques for treating the disorder and its complications. A recent meta-analysis of mortality studies by Dekkers and colleagues has confirmed that more recent reports have found lower mortality estimates compared with earlier findings (2). The purpose of the present study was to confirm and extend the findings of Dekkers et al. by concentrating on the relationship between biochemical measurements and mortality during follow-up after treatment.

\section{Methods}

\section{Mortality from acromegaly}

In January 2008, Medline was searched for all studies published between 1965 and 2008 using the terms 'acromegaly', 'mortality' and 'cause of death'. We also hand-searched abstracts of recent meetings of the US Endocrine Society, and the reference lists of retrieved studies and published reviews.

To be eligible for inclusion, the study must have presented mortality data for the group with acromegaly and the expected mortality for the population in the form of an SMR. A total of 325 papers and 20 abstracts were found related to mortality in acromegaly, and of these, 18 provided estimates of SMR (3-20). Two 
reports $(21,22)$ were subsequently updated either in a later study (12) or in an abstract report (9), thus only results from these latter publications were included in the analyses. Similarly, Ayuk and colleagues reported their findings concerning mortality of acromegaly in 2004 (6), but also provided additional information concerning mortality in abstract form (23). Data were extracted independently by two authors and any disagreements were resolved by consensus. The $95 \%$ CI for the SMR was recalculated wherever possible using the mid-exact P method (Openepi, www.openepi.com). Where insufficient data were reported to permit this calculation, the CIs reported in the paper were used.

\section{Mortality according to remission rates and serum levels of GH and insulin-like growth factor-I (IGF-I)}

Eligible studies were reviewed for reporting of SMR estimates according to remission rates and measured levels of GH or IGF-I following treatment. Twelve studies $(3,5-8,10-13,17,18,20)$ reported information on biochemical remission of acromegaly. We grouped these studies into higher remission $(>70 \%)$ and lower remission $(<70 \%)$ groups using the individual authors' definition of remission. The criteria for remission used by the study authors in the different reports were various groupings of post-treatment serum $\mathrm{GH}$ levels with or without IGF-I measurements. The division above or below biochemical remission rates of $70 \%$ was chosen arbitrarily based on analysis of reports of biochemical remission following pituitary surgery for acromegaly, where an average remission rate of $53 \%$ was noted, but with a minority describing remission in more than $70 \%$ of cases (1). Five older studies $(4,9,14$, $15,19,22)$ did not provide biochemical data for remission but are very likely to have had relatively low rates of biochemical remission as defined by modern criteria. We therefore included these studies in the lower remission group.

Nine studies reported SMR data for mortality divided according to serum $\mathrm{GH}$ levels at last follow-up after treatment $(3,5,7,8,10,12,13,15,18)$, and one abstract reported an SMR value for those with elevated GH levels $(>2.5 \mu \mathrm{g} / \mathrm{l})$ at last follow-up (23). In six of these studies, specific estimates of mortality were provided according to $\mathrm{GH}$ levels above and below various arbitrary cut-off points. In four studies $(5,7$, $13,15)$, mortality was divided above or below a posttreatment GH level of $2.5 \mu \mathrm{g} / \mathrm{l}$; in one study (12), the GH cut-off point was $2 \mu \mathrm{g} / \mathrm{l}$; and in another report, the GH level was $5 \mu \mathrm{g} / \mathrm{l}$ (3). However, in this latter study, $82 \%$ of those with GH at last follow-up $<5 \mu \mathrm{g} / \mathrm{l}$ were also $<$ $2.5 \mu \mathrm{g} / \mathrm{l}$. For the purposes of this analysis, these six studies have been grouped to provide mortality estimates for 'serum GH greater than or less than $2.5 \mu \mathrm{g} / \mathrm{l}$ '. In addition, three studies $(8,10,18)$ included a mortality cut-off point for $\mathrm{GH}$ of $2.5 \mu \mathrm{g} / \mathrm{l}$ in a composite biochemical end point of remission, which also included IGF-I greater than or less than normal, and glucose-suppressed $\mathrm{GH}$ greater than or less than $1 \mu \mathrm{g} / \mathrm{l}$. These latter three studies have also been included in the analysis, although it is unclear exactly how many individuals met just the $2.5 \mu \mathrm{g} / \mathrm{l}$ cut-off point in the remission/non-remission groups. In three of the above studies, the group classified here as ' $>2.5 \mu \mathrm{g} / \mathrm{l}$ ' were patients with final GH $2-5 \mu \mathrm{g} / \mathrm{l}(12), 2.5-5 \mu \mathrm{g} / \mathrm{l}$ (5) or $2.5-9.9 \mu \mathrm{g} / \mathrm{l}(15)$ and data for the whole group with $\mathrm{GH}>2.5 \mu \mathrm{g} / \mathrm{l}$ were not provided. In one study, serum GH was reported as the mean of a day profile of $\mathrm{GH}$ (7), and in the remainder GH was either measured in random serum samples or the sampling technique was not clear.

Five studies reported SMR data according to normal or elevated levels of serum IGF-I at last follow-up $(8,12$, 13, 17, 18); and in one study, the SMR estimate was restricted to those with normal IGF-I alone (10). In all of these studies, the normal range of IGF-I was adjusted according to age and sex. In four studies $(10,12,13$, 17), SMR data were reported according to IGF-I greater than or less than normal; and in two studies $(8,18)$, IGF-I measurements were included as a composite remission end point also including random serum GH and glucose-suppressed serum GH. As with the assessment of mortality according to random serum $\mathrm{GH}$ measurements in these reports, these latter two studies have been included in the IGF-I analysis; although it is unclear as to exactly what number of individuals specifically had normal or elevated IGF-I levels.

\section{Statistical analysis}

Pooled SMR estimates were calculated for all eligible studies using a fixed effects model. In the presence of significant heterogeneity $(P<0.10)$, a random effects model was also run in an attempt to incorporate the differences between studies into the analysis. Funnel plots for each model were inspected and no evidence of publication bias was evident (data not shown). Groups with different SMRs were compared by the method of Armstrong (24), assuming that the age-specific rates of death were proportional to the rates in the reference population in the various studies. All tests were twotailed; a $P$ value of $<0.05$ was considered statistically significant and $95 \% \mathrm{CI}$ are presented. All analyses were carried out using Review Manager (RevMan, Version 4.2 for Windows, The Cochrane Collaboration).

\section{Results}

SMR estimates for subjects with acromegaly are shown in Fig. 1, drawn from 18 studies totalling 4806 patients and including 1116 deaths during follow-up. Despite the fact that almost all of these individuals had 


\begin{tabular}{|c|c|c|c|}
\hline Study & \multicolumn{2}{|c|}{$\begin{array}{l}\text { Standardized mortality ratio } \\
\text { (random) }[95 \% \mathrm{Cl}]\end{array}$} & $\begin{array}{l}\text { Weight } \\
(\%)\end{array}$ \\
\hline Wright 1970 & 4 & $1.9[1.4,2.5]$ & 6.5 \\
\hline Alexander 1980 & & $3.3[2.4,4.5]$ & 6.2 \\
\hline Nabarro 1987 & & $1.3[0.9,1.9]$ & 5.6 \\
\hline Bates 1993 & & $2.7[1.8,4.0]$ & 5.4 \\
\hline Etxabe 1993 & & $3.2[1.6,6.3]$ & 3.0 \\
\hline Abosch 1998 & & $1.3[0.9,1.9]$ & 5.6 \\
\hline Orme 1998 & & $1.6[1.4,1.8]$ & 8.2 \\
\hline Shimatsu 1998 & & $2.1[1.7,2.6]$ & 7.4 \\
\hline Swearingen 1998 & & $1.2[0.6,2.4]$ & 3.0 \\
\hline Bengtsson 1999 & & $1.8[1.5,2.2]$ & 7.8 \\
\hline Arita 2003 & & $1.2[0.6,2.4]$ & 3.0 \\
\hline Beauregard 2003 & & $2.1[1.3,3.4]$ & 4.6 \\
\hline Ayuk 2004 & & $1.3[1.0,1.7]$ & 6.9 \\
\hline Biermasz 2004 & & $1.3[0.9,1.9]$ & 5.6 \\
\hline Holdaway 2004 & & $2.7[2.1,3.5]$ & 6.9 \\
\hline Kauppinen-Makelin 2005 & & $1.2[0.9,1.6]$ & 6.5 \\
\hline Trepp 2005 & & $1.3[0.7,2.4]$ & 3.3 \\
\hline Bex 2007 & & $1.4[0.9,2.2]$ & 4.8 \\
\hline $\begin{array}{c}\text { Total } \\
\text { Test for heterogeneity: } I^{2}=73 \%, P<0.0\end{array}$ & & $1.7[1.5,2.0]$ & $P<0.00001$ \\
\hline 0.5 & 2 & 10 & \\
\hline $\begin{array}{l}\text { Favours decreased } \\
\text { mortality in acromegaly }\end{array}$ & $\begin{array}{l}\text { Favours increa } \\
\text { mortality in acror }\end{array}$ & & \\
\hline
\end{tabular}

Figure 1 Pooled standardized mortality ratios (SMRs) in studies of acromegaly. Data are SMR (95\% confidence interval). undergone treatment for the disorder, mortality was significantly increased (SMR 1.7, 95\% CI 1.5, 2.0).

Figure 2 shows the SMR estimates for the 17 studies that reported remission data (as assessed by the individual study authors), grouped by the rate of biochemical remission. Those studies claiming $>70 \%$ remission rate following treatment had a pooled SMR of $1.2(95 \%$ CI 1.0, 1.5) compared with SMR of $2.0(95 \%$ CI 1.6, 2.3) for those studies with (or likely to have had) a lower remission rate (risk ratio $1.7, P<0.05$ ). These results were not significantly altered if the older studies where remission data were not provided were omitted from the analysis.

Figure 3 shows the SMR estimates from ten studies grouped according to final $\mathrm{GH}$ level following treatment. Mortality was close to the expected level when final GH was $<2.5 \mu \mathrm{g} / \mathrm{l}$ (SMR 1.1, 95\% CI 0.9, 1.4), but was significantly elevated in those with final $\mathrm{GH}>2.5 \mu \mathrm{g} / \mathrm{l}$ (SMR 1.9, 95\% CI 1.5, 2.4). The risk ratio for a serum $\mathrm{GH}>2.5 \mu \mathrm{g} / \mathrm{l}$ was $1.7(P<0.05)$. When the three studies reporting final $\mathrm{GH}$ level as part of a composite end point were excluded from the analysis, the results were similar $(<2.5 \mu \mathrm{g} / \mathrm{l}$ SMR $1.0,95 \%$ CI $0.7,1.5$; $>$ $2.5 \mu \mathrm{g} / \mathrm{l}$ SMR $1.7,95 \%$ CI 1.4, 2.1). No study reported mortality subdivided according to levels of $\mathrm{GH}$ during oral glucose tolerance test (OGTT) alone, although in three studies $(8,10,18)$ serum GH greater than or less than $1 \mu \mathrm{g} / \mathrm{l}$ after OGTT was included as part of a composite remission end point. When these studies were analysed as if OGTT GH level was the sole remission variable, SMR values were $1.2(95 \%$ CI $0.9,1.7)$ for $\mathrm{GH}$ $<1 \mu \mathrm{g} / \mathrm{l}$ and 2.3 (95\% CI 1.0, 5.3) for $\mathrm{GH}>1 \mu \mathrm{g} / \mathrm{l}$.

Figure 4 shows the SMR estimates from six studies grouped according to normal or elevated IGF-I at last follow-up. Those with normal IGF-I had mortality close to the expected values for the general population (SMR $1.1,95 \%$ CI 0.9, 1.4), whereas the SMR for those with elevated IGF-I at last follow-up remained significantly increased (SMR 2.5, 95\% CI 1.6, 4.0). The risk ratio for an elevated serum IGF-I was $2.3(P<0.05)$. If the analysis was restricted to just those studies reporting IGF-I alone as the remission end point (excluding those studies where IGF-I measurements were part of a composite end point), the figures were similar (normal IGF-I SMR 1.1, 95\% CI 0.8, 1.5; raised IGF-I SMR 2.3, 95\% CI 1.4, 3.8).

Medical treatment of acromegaly using somatostatin receptor analogues (SSRAs), either as primary treatment or as adjuvant therapy following unsuccessful pituitary surgery, became widespread in most countries in the 1990 s or later. Six studies $(3,5,10,13,17,18)$ reported $>30 \%$ use of SSRAs for patients not in remission following surgery, six studies $(4,7,9,11$, $14,19)$ were completed before widespread use of these agents, three studies reported very low/zero usage $(6,8$, $12)$, while in two studies $(15,16)$ the extent of use of SSRAs is uncertain. Grouping the studies according to $>30 \%$ use of SSRAs or $<30 \%$ use of SSRAs produces 


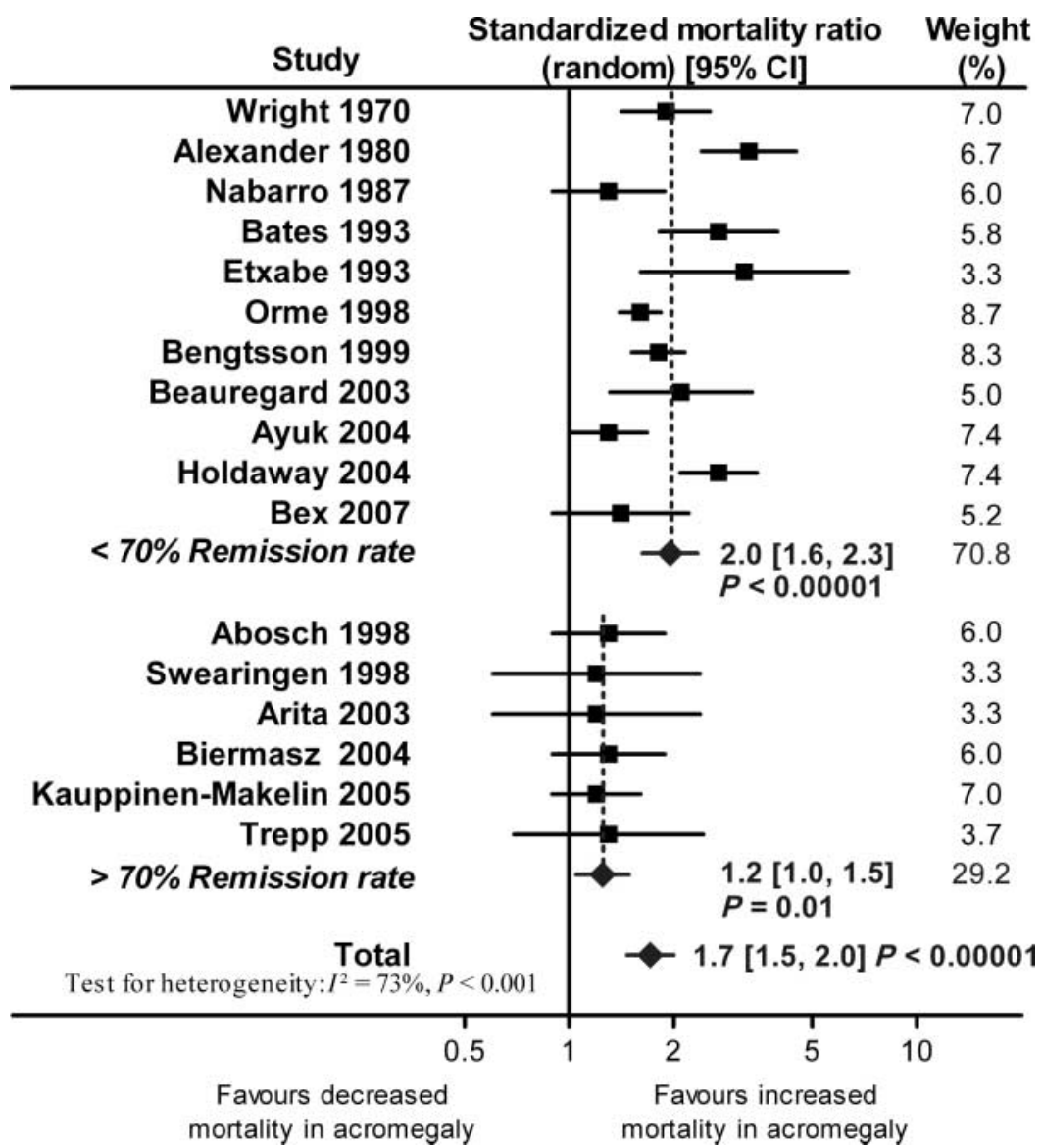

Figure 2 Pooled standardized mortality ratios (SMRs) in studies of acromegaly grouped according to actual or likely remission rate. Data are SMR (95\% confidence interval). the same subgroups as grouping the studies by remission rates shown in Fig. 2, with the same difference in SMR.

Finally, to determine whether mortality has changed in more recent studies, the studies were ranked according to the mean calendar year in which subjects were entered. The pooled SMR for the six studies $(4,7$, $9,11,12,14,19,22)$ with mean year of patient entry before 1984 was $2.2(95 \%$ CI $1.8,2.8)$ compared with SMR of $1.3(95 \%$ CI $1.1,1.6)$ in the seven studies $(3,5$, $8,10,13,17,18)$ with mean year of entry after 1984 $(P<0.05)$.

\section{Discussion}

A recent meta-analysis of mortality in acromegaly reported by Dekkers et al. (2) confirmed that acromegaly carries a significantly increased mortality despite treatment. In the New Zealand acromegalic cohort (12), which had an SMR of 2.7, overall life expectancy was reduced by 20 years, although this estimate could be biased to some extent by movement in life expectancy over the time of follow-up. Although age- and sexmatched reference populations were not available to calculate the same data for the entire group of studies, it would be reasonable to suppose that similar reductions in life expectancy would be seen in other patient populations. However, as shown here, more recent studies, and those reporting high rates of biochemical remission as judged by individual authors, have mortality closer to levels expected for the general population, suggesting a significant effect from modern treatment of the condition and its complications. Of significance, studies reporting greater use of somatostatin analogues appear to have significantly lower mortality. The present analysis has focused on the relationship between mortality and the serum levels of IGF-I and GH achieved by treatment, since these variables are commonly used by clinicians as biochemical markers of the activity of acromegaly. The findings indicate that reduction of serum GH to < $2.5 \mu \mathrm{g} / \mathrm{l}$, measured by RIA, or normalization of serum IGF-I for age and sex is associated with mortality indistinguishable from the general population, whereas a higher level of these hormones carries a significant mortality risk. The number of individuals in these studies is, however, sufficiently less so that a residual increased mortality in those with serum GH below $2.5 \mu \mathrm{g} / \mathrm{l}$ or normal IGF-I concentrations cannot be 


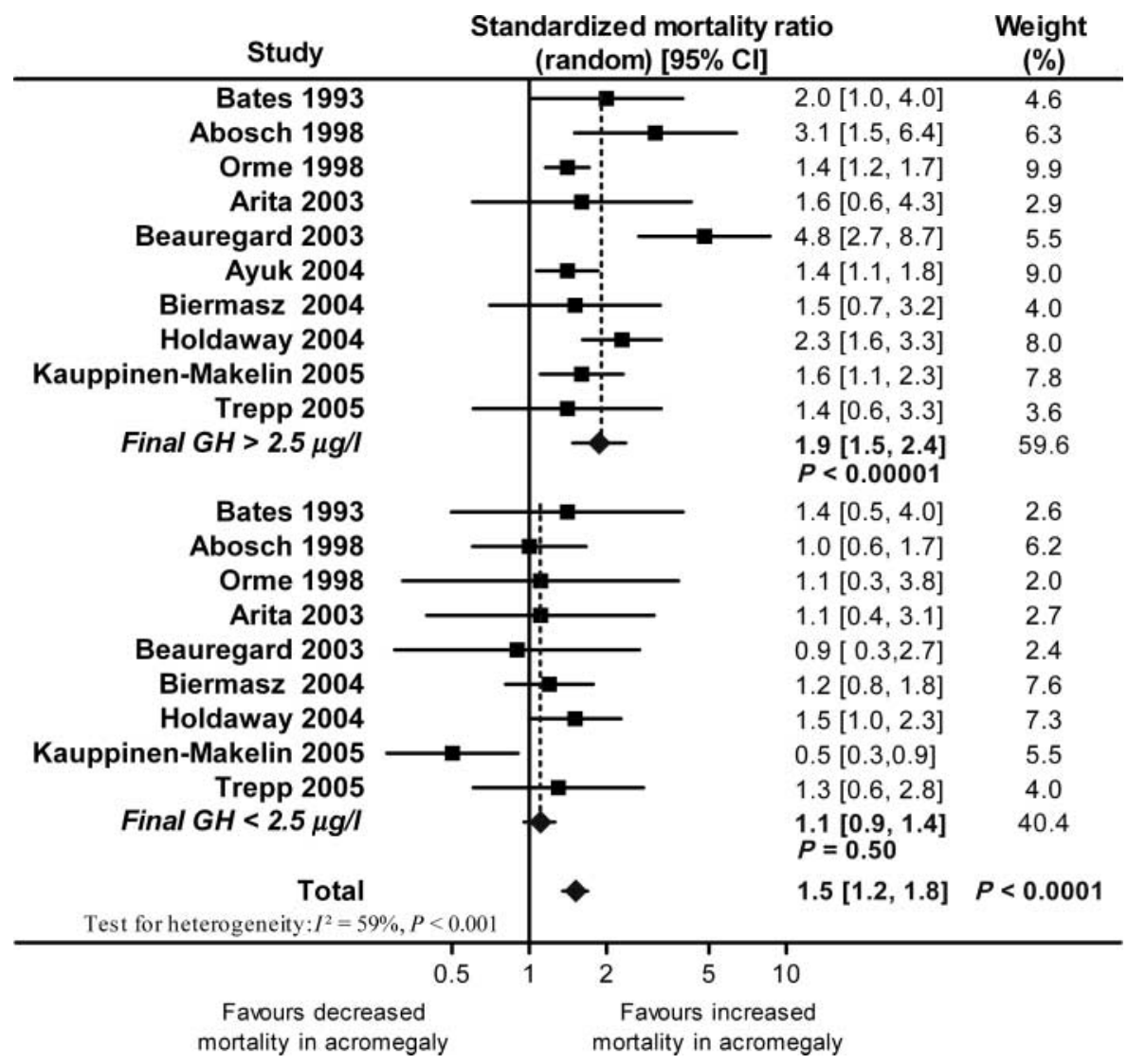

Figure 3 Pooled standardized mortality ratios (SMRs) in studies of acromegaly grouped according to $\mathrm{GH}$ level at final follow-up. Data are SMR (95\% confidence interval). excluded, as a result of previous tissue damage from increased GH and IGF-I levels prior to treatment.

In support of these findings, serum GH, and to a lesser extent serum IGF-I, has been identified in several studies as important determinants (often the major determinate) of mortality in acromegaly when assessed by multivariate analysis $(12,13,25)$. There is less data for IGF-I than for GH in this respect, although one study found IGF-I to have a significant influence on mortality in a multivariate analysis when substituted for $\mathrm{GH}$ in the assessment (12). However, two studies have not found IGF-I to be a significant independent predictor of mortality when assessed by relative mortality risk for those with normal compared with elevated IGF-I measurements $(6,13)$. Two studies $(12,13)$ have performed detailed multivariate analysis of factors that could potentially influence mortality in acromegaly (Table 1). Both found $\mathrm{GH}$ at last follow-up was the strongest predictor of outcome, and one study (12) found that IGF-I became a strong predictor of survival if substituted for GH in the analysis. The second study (13) did not find IGF-I to be an independent predictor of mortality, even when IGF-I replaced GH in the model. The number of patients in the studies in whom IGF-I measurements were performed was substantially less than the number with GH data, which may explain why in some instances serum IGF-I did not appear to be a significant predictor of survival. Other variables found to influence outcome included the presence of hypertension, duration of the disorder prior to treatment, age, and whether $\mathrm{GH}$ excess was due to a pituitary microadenoma (Table 1). The duration of the disorder prior to diagnosis has also been found to influence mortality in an analysis adjusted for age and sex (10).

Variables influencing mortality in acromegaly have been assessed in some studies by estimating the relative risk of mortality according to the presence or absence of various potential risk factors. In this type of analysis, conventional pituitary radiotherapy has been identified as a possible risk factor for mortality $(6,25)$. In a further study (20), there was a significant increase in SMR in irradiated patients compared with non-irradiated individuals, although another two studies reporting SMR data according to use/non-use of radiotherapy did not find a significant increase in SMR in the irradiated group when adjusted for age and sex (10) or multiple variables (13).

Although mortality from cardiovascular disease was found to be increased in acromegaly in several studies $(4,12,14,22)$, the only cardiac risk factor identified in multivariate analysis that might directly impact on mortality was hypertension (Table 1). However, it is likely that low patient numbers or incomplete data have underemphasized a potential influence of other classical 


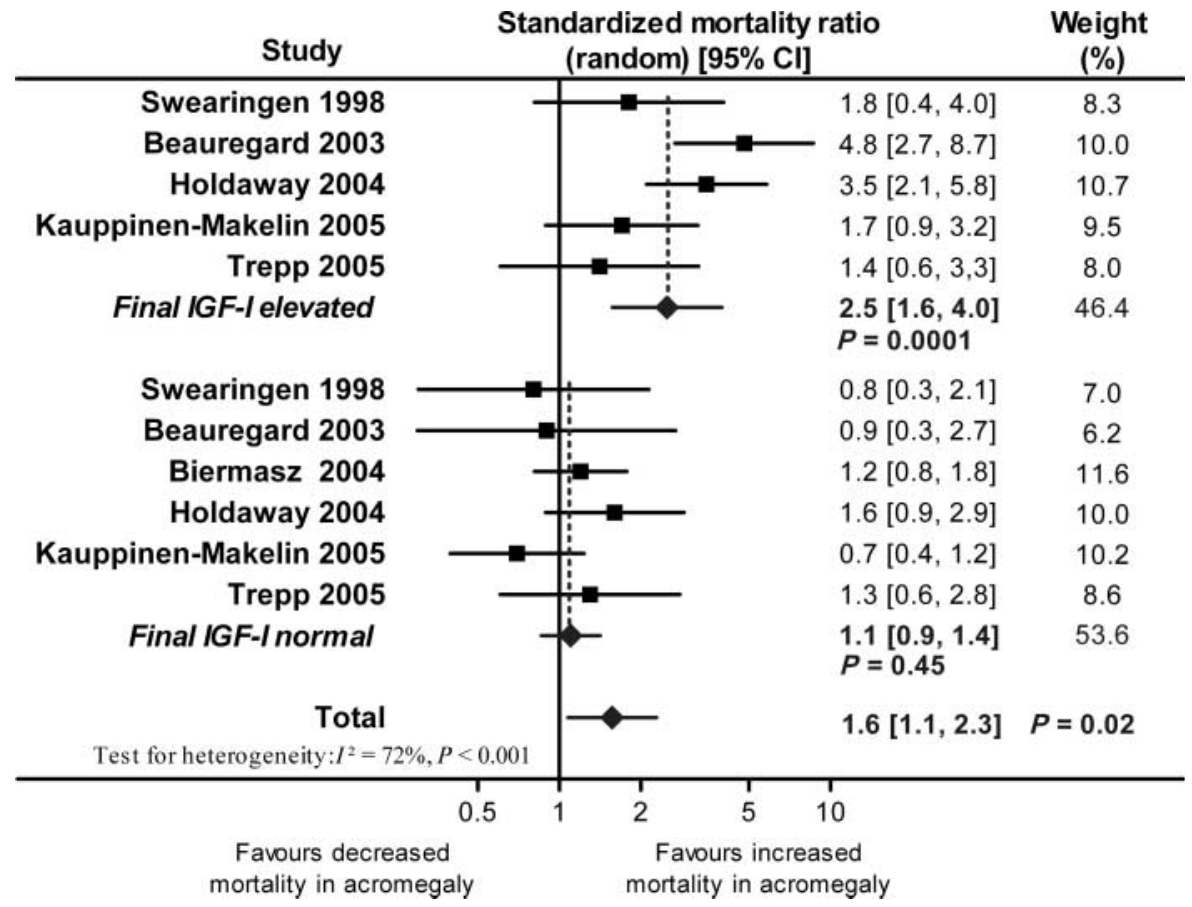

Figure 4 Pooled standardized mortality ratios (SMRs) in studies of acromegaly grouped according to IGF-I level at final follow-up. Data are SMR (95\% confidence interval). cardiovascular risk factors on mortality, such as diabetes, smoking and dyslipidaemia. However, the apparent lack of impact of traditional cardiac risk factors, in the face of elevated cardiovascular mortality in acromegaly, emphasizes the specific deleterious effect of increased serum levels of GH and IGF-I on cardiac function as detailed by Colao et al. (26). A possible increased death rate in acromegaly from stroke has also been identified in several studies $(4,6,14,19)$, and a potential relationship between use of radiotherapy and stroke has been suggested in acromegalic individuals (6). The presence of hypertension as a mortality risk factor in multivariate analysis (12) suggests an influence of this variable on mortality from stroke in these patients. It also remains possible that

Table 1 Variables affecting mortality in acromegaly assessed by multivariate analysis.

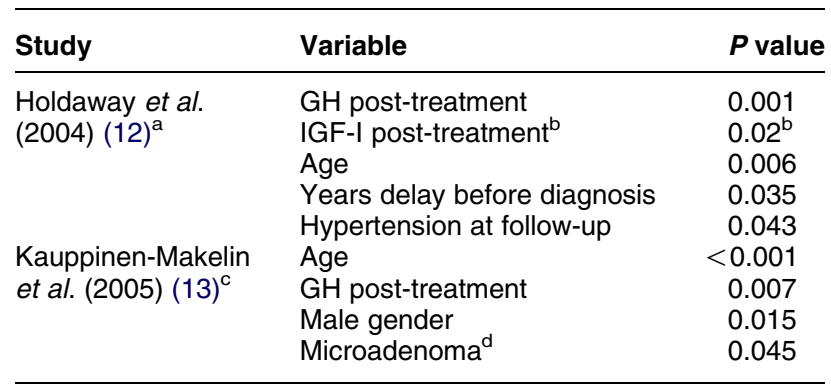

${ }^{a}$ Variables tested were GH, IGF-I, age, gender, hypertension, diabetes, arthritis, hypopituitarism and years delay before diagnosis.

${ }^{b}$ Value obtained when IGF-I was substituted for GH in the model.

${ }^{c}$ Variables tested were GH, IGF-I, age, gender, radiotherapy, tumour size, use of $\mathrm{GH}$ lowering medication and use of surgery.

${ }^{\mathrm{d}}$ Assessed after controlling for post-treatment GH and IGF-I. microvascular abnormalities specific to acromegaly $(27,28)$ may contribute to deaths from stroke in this condition.

The present analysis identifies serum GH and IGF-I as important variables contributing to the increased mortality of acromegaly, and correction of overproduction of these hormones appears to return mortality to expected levels for the general community. Uncertainty remains, however, about the translation of GH levels from the studies reported here, mainly measured by relatively insensitive GH RIAs which are no longer in use, to GH data generated by modern- or ultra-sensitive two-site sandwich immunoassays for GH. The listed studies employed competitive RIA up until the early-mid 1990s in most instances, and sensitive two-site noncompetitive assays were only used for a minority of patient assessments. Information helpful for the comparison of results using these different types of assay comes from the New Zealand study (12) where, in the process of updating data prior to closure of the study, living patients frequently had measurements performed using a sensitive chemiluminescent assay with detection limit $0.05 \mu \mathrm{g} / \mathrm{l}$. When the subjects in this study were divided according to different GH levels, the lowest mortality, indistinguishable from the general New Zealand population when assessed by Kaplan-Meier plot, was seen in those with final GH $<1 \mu \mathrm{g} / \mathrm{l}$. This supports the likelihood that remission levels of $\mathrm{GH}$, associated with normal life expectancy, will need to be lower than found by RIA in the studies reviewed here, when measured by more sensitive techniques. Further mortality studies solely employing modern $\mathrm{GH}$ assays are needed to address this point. In the 
meantime, it would be reasonable for clinicians to aim for their acromegalic patients to achieve normal IGF-I levels, random $\mathrm{GH}$ by modern assays $<1 \mu \mathrm{g} / \mathrm{l}$ and/or normal GH following OGTT (probably $<0.4 \mu \mathrm{g} / \mathrm{l}$ by chemiluminescent GH assay (29) or $<0.14 \mu \mathrm{g} / \mathrm{l}$ by ultrasensitive $\mathrm{GH}$ assay (30)).

\section{References}

1 Holdaway IM. Treatment of acromegaly. Hormone Research 2004 62 (Suppl 3) 79-92.

2 Dekkers OM, Biermasz NR, Pereira AM, Romijn JA \& Vandenbroucke JP. Mortality in acromegaly: a meta-analysis. Journal of Clinical Endocrinology and Metabolism 2008 93 61-67.

3 Abosch A, Tyrrell JB, Lamborn KR, Hannegan LT, Applebury CB \& Wilson CB. Transsphenoidal microsurgery for growth hormonesecreting pituitary adenomas: initial outcome and long-term results. Journal of Clinical Endocrinology and Metabolism $1998 \mathbf{8 3}$ 3411-3418.

4 Alexander L, Appleton D, Hall R, Ross WM \& Wilkinson R. Epidemiology of acromegaly in the Newcastle region. Clinical Endocrinology 198012 71-79.

5 Arita K, Kurisu K, Tominaga A, Eguchi K, Iida K, Uozumi T \& Kasagi F. Mortality in 154 surgically treated patients with acromegaly - a 10-year follow-up survey. Endocrine Journal 2003 50 163-172.

6 Ayuk J, Clayton RN, Holder G, Sheppard MC, Stewart PM \& Bates AS. Growth hormone and pituitary radiotherapy, but not serum insulin-like growth factor-I concentrations, predict excess mortality in patients with acromegaly. Journal of Clinical Endocrinology and Metabolism 200489 1613-1617.

7 Bates AS, Van't Hoff W, Jones JM \& Clayton RN. An audit of outcome of treatment in acromegaly. Quarterly Journal of Medicine $199386293-299$.

8 Beauregard C, Truong U, Hardy J \& Serri O. Long-term outcome and mortality after transsphenoidal adenomectomy for acromegaly. Clinical Endocrinology $2003 \mathbf{5 8} 86-91$.

9 Bengtsson BA, Jonsson B \& Nilsson B. Increased mortality in acromegaly is mainly caused by cardiovascular diseases, Abstracts of the 81st Annual Scientific Meeting US Endocrine Society 1999 P3-648.

10 Biermasz NR, Dekker FW, Pereira AM, van Thiel SW, Schutte PJ, van Dulken H, Romijn JA \& Roelfsema F. Determinants of survival in treated acromegaly in a single center: predictive value of serial insulin-like growth factor I measurements. Journal of Clinical Endocrinology and Metabolism 200489 2789-2796.

11 Etxabe J, Gaztambide S, Latorre P \& Vazquez JA. Acromegaly: an epidemiological study. Journal of Endocrinological Investigation 1993 16 181-187.

12 Holdaway IM, Rajasoorya RC \& Gamble GD. Factors influencing mortality in acromegaly. Journal of Clinical Endocrinology and Metabolism $200489667-674$.

13 Kauppinen-Makelin R, Sane T, Reunanen A, Valimaki MJ, Niskanen L, Markkanen H, Loyttyniemi E, Ebeling T, Jaatinen P, Laine H, Nuutila P, Salmela P, Salmi J, Stenman UH, Viikari J \& Voutilainen E. A nationwide survey of mortality in acromegaly. Journal of Clinical Endocrinology and Metabolism 200590 4081-4086.

14 Nabarro JD. Acromegaly. Clinical Endocrinology 198726 481-512.

15 Orme SM, McNally RJ, Cartwright RA \& Belchetz PE. Mortality and cancer incidence in acromegaly: a retrospective cohort study. United Kingdom Acromegaly Study Group. Journal of Clinical Endocrinology and Metabolism $1998 \mathbf{8 3} 2730-2734$.
16 Shimatsu A, Yokogoshi Y, Saito S, Shimizu N \& Irie M. Long-term survival and cardiovascular complications in patients with acromegaly and pituitary gigantism. Journal of Endocrinological Investigation 199821 55-57.

17 Swearingen B, Barker FG II, Katznelson L, Biller BM, Grinspoon S, Klibanski A, Moayeri N, Black PM \& Zervas NT. Long-term mortality after transsphenoidal surgery and adjunctive therapy for acromegaly. Journal of Clinical Endocrinology and Metabolism 1998 83 3419-3426.

18 Trepp R, Stettler C, Zwahlen M, Seiler R, Diem P \& Christ ER. Treatment outcomes and mortality of 94 patients with acromegaly. Acta Neurochirurgica $2005 \mathbf{1 4 7}$ 243-251 (discussion 250-241).

19 Wright AD, Hill DM, Lowy C \& Fraser TR. Mortality in acromegaly. Quarterly Journal of Medicine 197039 1-16.

20 Bex M, Abs R, T'Sjoen G, Mockel J, Velkeniers B, Muermans K \& Maiter D. AcroBel - the Belgian registry on acromegaly: a survey of the 'real-life' outcome in 418 acromegalic subjects. European Journal of Endocrinology 2007157 399-409.

21 Rajasoorya C, Holdaway IM, Wrightson P, Scott DJ \& Ibbertson HK. Determinants of clinical outcome and survival in acromegaly. Clinical Endocrinology 199441 95-102.

22 Bengtsson BA, Eden S, Ernest I, Oden A \& Sjogren B. Epidemiology and long-term survival in acromegaly. A study of 166 cases diagnosed between 1955 and 1984. Acta Medica Scandinavica 1988223 327-335.

23 Ayuk J, Clayton RN, Sheppard MC, Stewart PM \& Bates AS. Outcomes in acromegaly: a retrospective study of 419 patents from the West Midlands region of the United Kingdom, Abstracts of the 85th Annual Scientific Meeting US Endocrine Society 2003 126.

24 Armstrong BG. Comparing standardized mortality ratios. Annals of Epidemiology 19955 60-64.

25 Mestron A, Webb SM, Astorga R, Benito P, Catala M, Gaztambide S, Gomez JM, Halperin I, Lucas-Morante T, Moreno B, Obiols G, de Pablos P, Paramo C, Pico A, Torres E, Varela C, Vazquez JA, Zamora J. Albareda M \& Gilabert M. Epidemiology, clinical characteristics, outcome, morbidity and mortality in acromegaly based on the Spanish Acromegaly Registry (Registro Espanol de Acromegalia, REA). European Journal of Endocrinology 2004151 439-446.

26 Colao A, Ferone D, Marzullo P \& Lombardi G. Systemic complications of acromegaly: epidemiology, pathogenesis, and management. Endocrine Reviews 200425 102-152.

27 Schiavon F, Maffei P, Martini C, De Carlo E, Fais C, Todesco S \& Sicolo N. Morphologic study of microcirculation in acromegaly by capillaroscopy. Journal of Clinical Endocrinology and Metabolism 199984 3151-3155.

28 Brevetti G, Marzullo P, Silvestro A, Pivonello R, Oliva G, di Somma C, Lombardi G \& Colao A. Early vascular alterations in acromegaly. Journal of Clinical Endocrinology and Metabolism 2002 87 3174-3179.

29 Minuto F, Resmini E, Boschetti M, Arvigo M, Sormani MP, Giusti M, Ferone D \& Barreca A. Assessment of disease activity in acromegaly by means of a single blood sample: comparison of the 120th minute postglucose value with spontaneous GH secretion and with the IGF system. Clinical Endocrinology 2004 61 138-144.

30 Freda PU, Nuruzzaman AT, Reyes CM, Sundeen RE \& Post KD. Significance of 'abnormal' nadir growth hormone levels after oral glucose in postoperative patients with acromegaly in remission with normal insulin-like growth factor-I levels. Journal of Clinical Endocrinology and Metabolism 200489 495-500.

Received 26 May 2008

Accepted 28 May 2008 